\title{
Development of a lower extremity model for high strain rate impact loading
}

\author{
Rebecca A. Fielding and Reuben H. Kraft* \\ Department of Mechanical and Nuclear Engineering, \\ Computational Biomechanics Group, \\ The Pennsylvania State University, \\ 341 Leonhard Building, University Park, PA 16802, USA \\ Email: rafielding@gmail.com \\ Email: reuben.kraft@psu.edu \\ *Corresponding author
}

Andrzej Przekwas and X.G. Tan

CFD Research Corporation, Huntsville, AL, 35805 USA

Email: ajp@cfdrc.com

Email:xgt@cfdrc.com

\begin{abstract}
In recent military conflicts, the incidence of underbody blasts has led to severe injuries, specifically in the lower extremities. The development of a lower extremity model may lead to a better understanding of injury patterns and mechanisms. A computational finite element model of the lower extremity was developed based on geometry made available in an anatomical repository. The portion of the extremity model below the knee was used in initial comparisons between simulations and experimental data. Impact was applied via a loading plate with a vertical velocity of $5 \mathrm{~m} / \mathrm{s}, 10 \mathrm{~m} / \mathrm{s}$, and $12 \mathrm{~m} / \mathrm{s}$. Resultant axial force was compared to experimental data. Results of these simulations fall within the range of available experimental data, which gives confidence that this model represents advancement in lower extremity modelling capabilities. Bone fracture has also been modelled and shows consistency with injuries typical of underbody blast scenarios.
\end{abstract}

Keywords: finite element modelling; computational mechanics; high strain rate; lower extremity; biomechanics; underbody blast; injury scoring; fracture mechanics; simulation; anatomical modelling; impact loading.

Reference to this paper should be made as follows: Fielding, R.A., Kraft, R.H., Przekwas, A. and Tan, X.G. (2015) 'Development of a lower extremity model for high strain rate impact loading', Int. J. Experimental and Computational Biomechanics, Vol. 3, No. 2, pp.161-186.

Biographical notes: Rebecca A. Fielding is a graduate student in the Department of Mechanical and Nuclear Engineering in the Computational Biomechanics Group at the Pennsylvania State University.

Reuben H. Kraft is a Shuman Assistant Professor of Mechanical Engineering in the Department of Mechanical and Nuclear Engineering at the Pennsylvania State University. 
Andrzej Przekwas co-founded the CFD Research Corporation and is the head of the Computational Medicine and Biology (CMB) Division.

X.G. Tan is a Senior Principal Engineer at the CFD Research Corporation.

\section{Introduction}

An 'underbody blast' (UBB) is the detonation of a mine or improvised explosive device (IED) underneath a vehicle. The explosion results in 'local' and 'global' effects. Local effects include inelastic deformations and the rapid acceleration of the vehicle floor following the blast. Global effects pertain to the gross motion of the vehicle, particularly in the vertical direction (Arepally et al., 2008). In recent military conflicts, the incidence of UBBs has led to severe injuries, specifically in the lower extremities (Alvarez, 2011; Ramasamy et al., 2014). During operation Iraqi freedom, the lower extremity accounted for $26 \%$ of all combat injuries, and $34 \%$ of those injuries were caused by explosive devices (McKay and Bir, 2009). In a review of 500 warriors wounded in action who were exposed to UBBs, almost $200(40 \%)$ had foot and ankle injures. Furthermore, the injury review showed 57 instances of talus fracture, 56 instances of tibia fracture, and at least 100 calcaneus fractures. Malleolar fractures were also noted (Pintar, 2012). Given the frequency and severity of UBB related lower extremity injuries, it is critical to better understand and protect against these injuries. Developing accurate models for use in UBB simulations may also allow for the modelling of other military-related lower extremity injuries.

Much of the work that exists for modelling lower extremity injuries has been developed for applications to the automotive industry. Though different in application, this work still represents an important basis in progressing human models. A lower leg model for automotive impact (Untaroiu and Shin, 2013) was validated against $5 \mathrm{~m} / \mathrm{s}$ experimental data by Funk et al. (2000), providing an example standard of quality for validating a new model. The Global Human Body Models Consortium (GHBMC), sponsored by seven auto manufacturers, has developed a geometrically accurate full body model of a mid-size male validated against a variety of automotive impact type tests (Gayzik et al., 2011). While the GHBMC model was developed for automotive applications, limited attempts have been made to appropriate the lower leg portion of this model for military applications, though it is suggested that modifications should be made to better suit the model to high strain rate applications (Gabler et al., 2014). Because automotive crashes may be represented with anthropomorphic testing devices (ATDs), some lower extremity modelling efforts seek to compare response of human body models with the response of ATD models to determine the applicability of these testing devices to blast applications. A study at the University of Cincinnati compared the response of a numerical HYBRID III ATD model to experimental data for lower extremity impact response and injury thresholds to determine the validity of using an ATD model to represent a blast scenario (Nilakantan and Tabiei, 2009). This study also examined the effects of initial pose on impact response, which is an important consideration. It was determined that extremity positioning has a significant effect on the impact response (Nilakantan and Tabiei, 2009). Similarly, a study at Wayne State University used a validated lower extremity model for comparisons with an ATD model under blast loading 
conditions. This study used two different poses for the lower extremity (Suresh and Zhu, 2012). Finally, steps have been taken to incorporate a simplistic boot model into a lower leg finite element model to better replicate real world UBB conditions (Qiu et al., 2011). In addition to modelling explosive impact to the lower extremity, progress has been made in modelling the effect of shock waves to the lower extremity during explosions. A lower extremity model developed based on CT images was used for this purpose and shows positive preliminary results (Bertucci et al., 2011).

Post-mortem human subject studies typically provide the experimental data against which human models are validated. For the lower extremity, a variety of impact data exists. Axial loading may be delivered to the leg via a vertical drop test (Henderson et al., 2013) or a piston and pendulum set up which transfers loading to a plate in contact with the foot (Funk et al., 2000; Mckay, 2010). A review of eight axial loading experiments shows loading rates between 2 and $12.5 \mathrm{~m} / \mathrm{s}$ with each experiment testing on 9 to 26 cadaver legs each. Four of these experiments were conducted on the lower extremity below the knee, three used the leg up to the mid-femur, and one used a full body (Mckay, 2010). An ongoing effort to develop a targeted military ATD, the Warrior Injury Assessment Manikin (WIAMan), has completed a range of cadaveric testing with conditions closely matched to real-world UBB scenarios (Chancey et al., 2011). Once completed, this project will provide state of the art experimental data for modelling efforts.

The research presented here seeks to expand upon existing modelling by studying the response of the anatomical model at a variety of loading rates including $5 \mathrm{~m} / \mathrm{s}$ (Funk et al., 2000) and 10 and $12 \mathrm{~m} / \mathrm{s}$ (Mckay, 2010). These high rate simulations are critical because understanding UBB incidents and injury thresholds requires modelling at rates in excess of $8 \mathrm{~m} / \mathrm{s}$ (Christopher, 2012). Furthermore, the researchers have modelled fracture using these simulations and compared to existing fracture locations. These fractures were then rated according to the abbreviated injury scale (AIS) (Lesko et al., 2010). The ability to predict and report fracture according to a quantitative injury scale gives value to the use of anatomical geometry and may contribute to communication between the medical and biomechanical community. In addition to studying the response of the lower extremity model at different loading rates, the experimenters also took several factors into account that may influence the response of the extremity model. Using a hierarchical modelling approach (Thacker et al., 2007; Kraft et al., 2012), the researchers compared the response of a lower extremity model below the knee to a full lower extremity model. A variety of extremity poses were also considered in studying the full extremity response. A sensitivity study was undertaken to compare the effect of different hyperelastic material constants in soft tissue, since there is a wide range reported in literature (Kraft et al., 2012; Untaroiu et al., 2005). The sole of a combat boot was incorporated into the model, as in a real world UBB scenario this personal protective equipment would be worn. Finally, the effects of mesh density on model response were studied.

\section{Methodology}

Anatomical models of the lower extremity, including the full lower extremity and the extremity below the knee, have been created based on a repository of anatomical 
geometry made available by the University of Tokyo (Mitsuhashi et al., 2009). This geometry was scaled and positioned appropriately using a surface editing software (Blender Foundation, 1995). Finite element meshes were developed using ANSYS ICEM CFD. Simulations of axial loading were conducted using LS-DYNA. Boundary conditions for these simulations were derived from experimental data. Simulations have been conducted at $5 \mathrm{~m} / \mathrm{s}$ (Funk et al., 2000), $10 \mathrm{~m} / \mathrm{s}$ (Mckay, 2010), and $12 \mathrm{~m} / \mathrm{s}$ (Mckay, 2010) and compared to those experimental results. These high rate simulations are critical because understanding UBB incidents and injury thresholds requires modelling at rates in excess of $8 \mathrm{~m} / \mathrm{s}$ (Christopher, 2012). Additional considerations have been taken into account, such as the effect of soft tissue parameters. The methodology to develop these models and simulations is described.

\subsection{Anatomy}

Geometry for the lower extremity model was derived from an anatomical dictionary made available by the Database Center for Life Science, a research institute at the University of Tokyo (Mitsuhashi et al., 2009). This anatomical resource provides geometry based on a full body MRI scan of a male volunteer. This MRI data was supplemented using medical textbooks, atlases, and anatomical drawings (Mitsuhashi et al., 2009). The full body model from this repository was utilised to develop surfaces for the lower extremity skeleton and soft tissue. Surface editing software was used to reposition the lower extremity as needed. The model was repositioned by rigging the surface geometry to a moveable frame. The upper portion of the lower extremity, the leg, and the foot were each assigned to a section of the moveable frame. The frame was positioned such that the lower extremity was bent to a realistic seated posture. Care was taken not to distort the bones during repositioning. Because the original surface geometry did not include a cortical shell and trabecular bone, this CAD software was also used to generate simplified trabecular bone sections for the femur, tibia, and the calcaneus. To create each trabecular bone section, the external bone geometry was replicated then scaled such that it was contained within original bone geometry.

To ensure a realistic model, the external geometry was compared to reported anthropometric data. The US Army Anthropometric Survey I (ANSUR I) completed 132 standard measurements of almost 9,000 subjects. The total sample population was down-sampled in order to represent the age and racial demographics of the active duty US Army personnel at the time of the survey. A total of 1,774 male and 2,208 female US Army personnel were represented by the final results of the survey (Gordon et al., 1989). The lower extremity model presented in this paper was compared to a 50th percentile male as reported by ANSUR I using a variety of relevant metrics for the lower extremity used in the survey. The measurements were taken using measuring tools available in the surface editing CAD software (Blender Foundation, 1995). The results of this comparison are shown in Table 1. The comparative measurements were considered a close match and no scaling was needed. The dimensions match as closely as $0.33 \%$, as seen in the lateral-malleous height. The greatest difference is seen in the foot length, showing a percent difference of $10.3 \%$. The complete anatomical model is shown and labelled in Figure 1. 
Table 1 Lower extremity model geometry was compared to 50th percentile male anthropometry as reported ANSUR I

\begin{tabular}{lccc}
\hline Dimension & ANSUR $(\mathrm{mm})$ & Leg model $(\mathrm{mm})$ & Percent difference \\
\hline Buttock-knee length & 616.4 & 554.1 & 10.1 \\
Buttock-popliteal length & 500.4 & 421.8 & 15.7 \\
Sitting knee height & 558.8 & 518.6 & 7.2 \\
Thigh clearance & 168.2 & 169.3 & 0.63 \\
Foot length & 269.7 & 241.9 & 10.3 \\
Bi-malleolar breadth & 72.8 & 69.9 & 4.1 \\
Lateral malleolus height & 67.1 & 67.3 & 0.33 \\
Foot breadth & 100.6 & 97.9 & 2.7 \\
\hline
\end{tabular}

Source: Gordon et al. (1989)

Figure 1 The full lower extremity with all anatomical components is shown (see online version for colours)

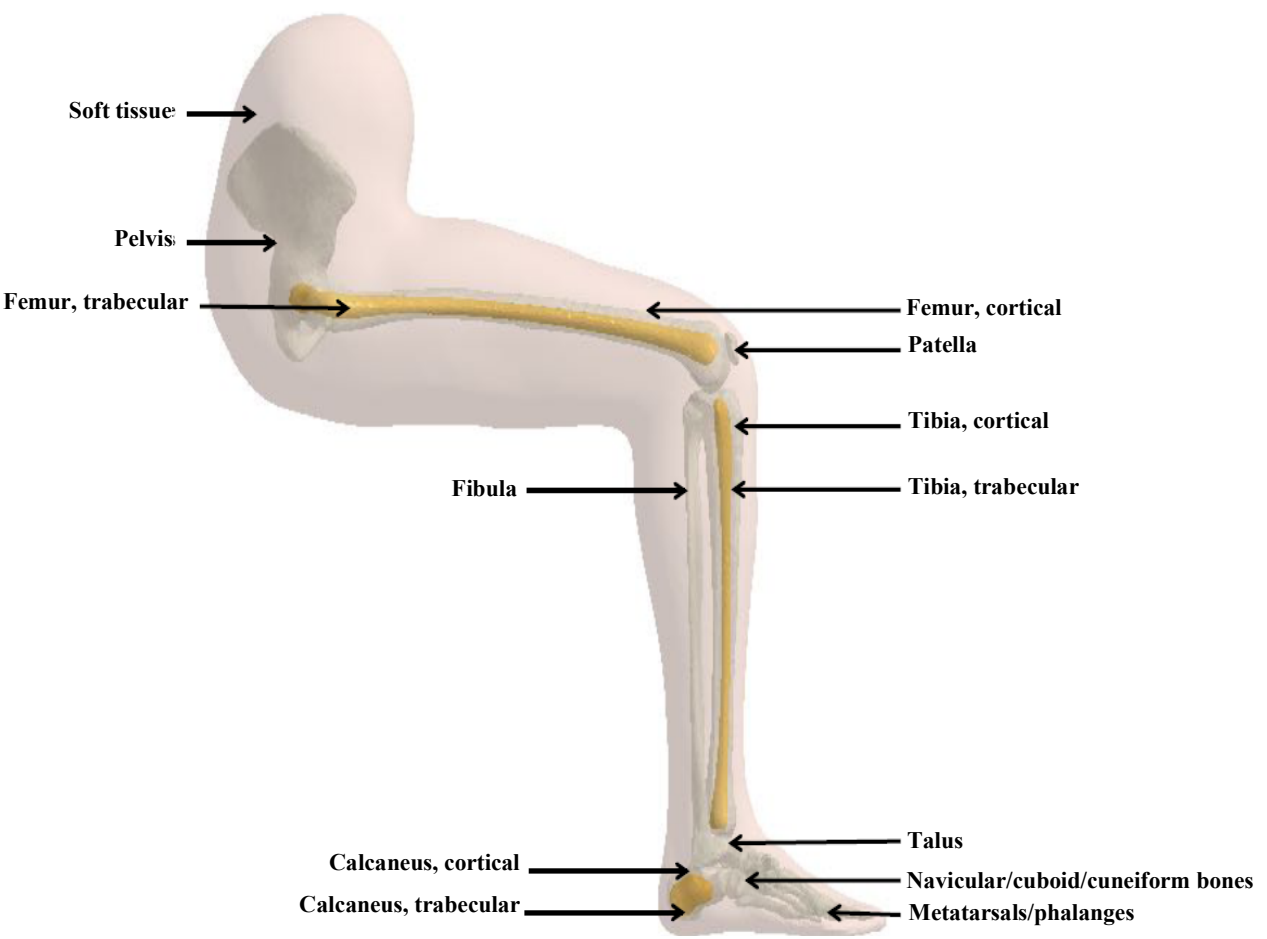

Material models for anatomical components were determined based on literature (Cox et al., 2007; Glozman and Azhari, 2010; Krone and Schuster, 2006; Untaroiu et al., 2005). Elastic-plastic material models are typical of bone modelling (Gabler et al., 2014; Suresh and Zhu, 2012; Untaroiu and Shin, 2013), thus the plastic-kinematic material model was chosen in the finite element software to capture this material behaviour. The parameters of this material model include density, Young's modulus, Poisson's ratio, yield stress, and tangent modulus. The tangent modulus quantifies the slope of the 
stress-strain curve after the yield stress is reached (LSTC, 2015a). In order to represent bone fracture over the course of simulations, an element erosion model was applied wherein elements no longer carry stress once a certain failure strain is exceeded (LSTC, 2015b). Yield strain was selected as the criterion for failure following the example of other fracture modelling presented in literature (Timmel et al., 2007; Kurtaran et al., 2003). The values for all material properties for cortical and trabecular bone are provided in Table 2. The element deletion method used here was reviewed by Song et al and compared to other methods, such as the extended finite element method (FEM) and cohesive elements. It was found that, while there are some deficiencies using element erosion, such as underestimation of crack speed and influence of mesh lines on crack propagation, the method is widely used in industry and able to predict major features of fracture (Song et al., 2008).

Soft tissue was modelled to include muscle, skin, and fatty tissue. The decision to represent all soft tissue as one material is justified by considering the complexity of explicitly modelling soft tissue components (muscle, fat, skin) versus the limited anticipated effects of the homogeneity on our analysis, relative to the effect of the overall parameters. Additionally, though ligaments, tendons, and cartilage were not explicitly modelled, shared nodes between the bones and the soft tissue connect the bones to one another and allows for distribution of stresses at the articulations of the anatomy. The soft tissue should also allow for flexion of the joints. The soft tissue was modelled as a Mooney-Rivlin hyperelastic material following examples found in literature supporting the use of this material model (Majumder et al., 2007; Lee et al., 2009; Hendriks et al., 2003; Lapeer et al., 2011). The Mooney-Rivlin material formulation is represented as follows (LSTC, 2015a):

$$
W=C_{1}\left(\tilde{I}_{1}-3\right)+C_{2}\left(\tilde{I}_{2}-3\right)+\boldsymbol{F}(\lambda)+\frac{1}{2} K[\ln (J)]^{2}
$$

Here, $W$ represents the uncoupled overall strain energy, the deviatoric invariants of the right Cauchy deformation tensor are given by $\tilde{I}_{1}$ and $\tilde{I}_{2}, \lambda$ represents the deviatoric stretch along the fibre direction, and $J$, the volume ratio, is defined as $J=\operatorname{det}(\boldsymbol{F})$. The Mooney-Rivlin coefficients are represented by $C_{1}$ and $C_{2}$, and $K$ is the bulk modulus (LSTC, 2015a). Values for all user-input soft tissue material parameters are given in Table 2.

One limitation of the current finite element model is the exclusion of viscoelasticity in the constitutive description of soft tissue, which is included in some soft tissue formulations (Gabler et al., 2014; Untaroiu et al., 2005). To model the progression of damage, it may be more accurate for the constitutive model to be extended to account for the strain-rate dependent behaviour of soft tissue. The exclusion may have an effect on the outcome of our results, potentially leading to larger shear stresses, but smaller shear strains. Future work will aim to study this strain-rate dependency. However, there is precedent for using hyperelastic material models (Lapeer et al., 2011; Cox et al., 2007), indicating that we may still be confident in the validity of our model. 
Table 2 Material properties for leg simulations with citations reporting the origins of this data

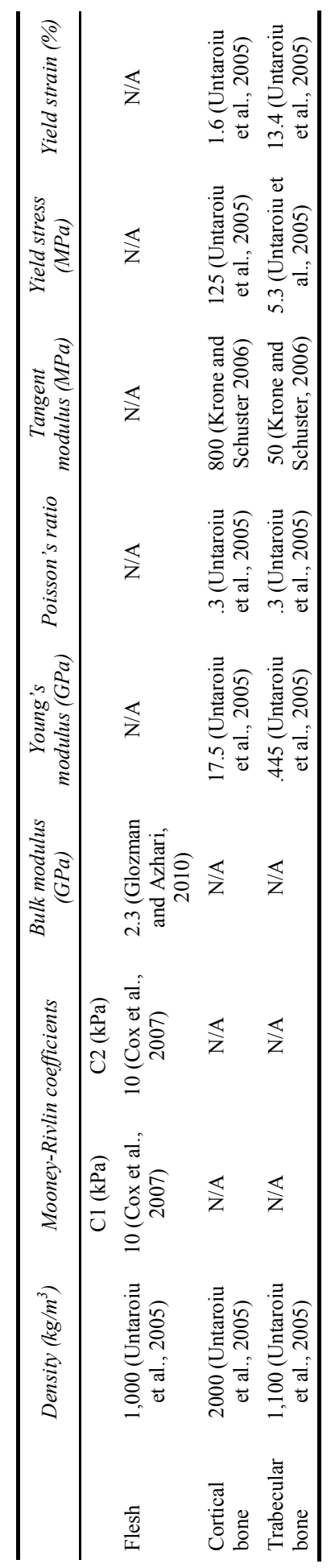




\subsection{Computational framework}

In replication of experimental lower extremity impact data, initial simulations were conducted with only the portion of the leg below the knee. The lower leg geometry included the flesh, cortical tibia, fibula, calcaneus, talus, mid-foot bones, and forefoot bones with metatarsals and phalanges fused together. In addition, simplified trabecular bone sections were incorporated for the tibia, and calcaneus. Other bones were modelled using cortical bone properties. This anatomy is illustrated in Figure 1.

Analysis was conducted using a Lagrangian formulation of the FEM, wherein dynamic equilibrium is enforced by means of the weak form of the principle of virtual work in the reference configuration:

$$
\int_{B_{0}} \boldsymbol{P}: \nabla_{0} \boldsymbol{\eta} d V_{0}+\int_{B_{0}} \rho_{0} \boldsymbol{b} \cdot \boldsymbol{\eta} d V_{0}+\int_{\partial B_{0}} \overline{\boldsymbol{t}} \cdot \boldsymbol{\eta} d S_{0}-\int_{B_{0}} \rho_{0} \boldsymbol{a} \cdot \boldsymbol{\eta} d V_{0}=0
$$

In this equation, $\boldsymbol{P}$ refers to the first Piola-Kirchoff stress tensor, $\nabla_{0}$ represents the material gradient, $\boldsymbol{\eta}$ is a virtual displacement which satisfies homogenous boundary conditions over $\partial B_{0}$, the : symbol indicates an inner product of second-order tensors, $\rho_{0}$ is the initial density, $\boldsymbol{b}$ represents body forces, $\overline{\boldsymbol{t}}$ represents tractions applied to $\partial B_{0}$, and $\boldsymbol{a}$ refers to acceleration. The internal forces in the body are represented by the first term of this equation. External work is represented by the second and third terms. The final term is representative of virtual work (Kraft et al., 2008). LS-DYNA was used for all simulations.

A mesh was generated of four noded tetrahedral elements, which were formulated as one point constant stress elements with nodal pressure averaging. This element formulation alleviates volume locking and shows similar deformation and force results as hexahedral element formulations (Bonet and Burton, 1998; Erhard, 2011). All soft tissue, cortical bone, and trabecular bone were represented with volume elements. The primary mesh used for simulations contained 168,768 elements ranging in size from 2 to $10 \mathrm{~mm}$. Contact was modelled using an eroding contact formulation for all components of the model wherein contact surfaces are updated when elements are removed (LSTC, 2015b).

\section{3 'Low rate' impact}

The first phase of this research sought to validate the lower leg model against the experiments of Funk et al. (2000). These simulations were conducted at a loading rate of $5 \mathrm{~m} / \mathrm{s}$, which is slower than a typical UBB (Mckay, 2010), and therefore here considered 'low rate'. In replication of the set-up of Funk's experiments, the leg was bolstered at the knee, loading was applied via a foam-padded plate in contact with the foot, and a peak velocity of $5 \mathrm{~m} / \mathrm{s}$ was reached $18 \mathrm{~ms}$ into the simulation then decreased to $0 \mathrm{~m} / \mathrm{s}$ by $22 \mathrm{~ms}$. These loading conditions are illustrated in Figure 2(a). This velocity profile is based on the description and results of Funk's impact experiments (Funk et al., 2000). The foam pad was modelled as low density foam with the material properties given in Table 3 (Dow Automotive, 2009). The behaviour of the foam padding was also controlled by a stress strain curve given in Appendix (Dow Automotive, 2009). 
Figure 2 (a) Boundary conditions are shown for 'low rate' impact simulations (b) Boundary conditions are shown for 'high rate' impact simulations (see online version for colours)

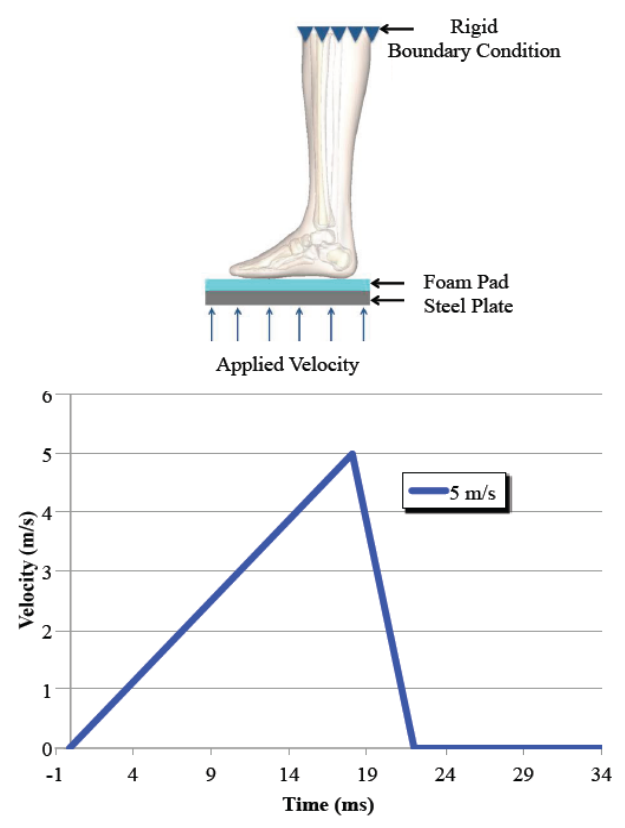

(a)

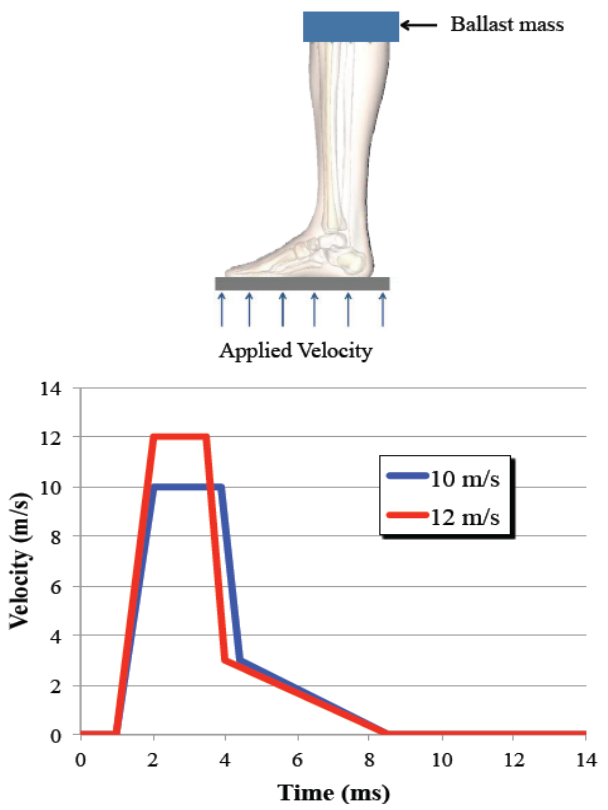

(b)

Source: Mckay (2010) and Funk et al. (2000)

Table 3 Material properties used to foam padding

\begin{tabular}{lccccc}
\hline & $\begin{array}{c}\text { Density } \\
\left(\mathrm{kg} / \mathrm{m}^{3}\right)\end{array}$ & $\begin{array}{c}\text { Young's } \\
\text { modulus }(\mathrm{MPa})\end{array}$ & $\begin{array}{c}\text { Hysteretic } \\
\text { unloadingfactor }\end{array}$ & $\begin{array}{c}\text { Viscous } \\
\text { coefficient }\end{array}$ & $\begin{array}{c}\text { Unloading } \\
\text { shape factor }\end{array}$ \\
\hline Foam pad & 37 & 10.5 & 0.101 & 0.225 & 15 \\
\hline
\end{tabular}

Source: Dow Automotive (2009)

\section{4 'High rate' impact}

Because UBBs occur at loading rates greater than $5 \mathrm{~m} / \mathrm{s}$ (Mckay, 2010), additional lower leg simulations were conducted at higher rates of $10 \mathrm{~m} / \mathrm{s}$ and $12 \mathrm{~m} / \mathrm{s}$ with results compared to experimental data collected by McKay (2010). In McKay's experiments, the lower leg was allowed to move in the axial direction but was limited in motion by the mass of the upper portion of the lower extremity. The foot was in contact with a steel loading plate. The loading device allowed for $24 \mathrm{~mm}$ of free flight before the loading plate was rapidly decelerated by a honeycomb structured material, so the plate is able to continue past its target intrusion at much lower loading rates. In the simulations, maximum velocity was reached at $2 \mathrm{~ms}$ and maintained until $24 \mathrm{~mm}$ of intrusion was achieved. Then, to represent the influence of the experimental honeycomb material, loading was rapidly decreased to $3 \mathrm{~m} / \mathrm{s}$ and continued to gradually decrease to $0 \mathrm{~m} / \mathrm{s}$ over the remainder of the simulation. The velocity curves and boundary conditions are shown in Figure 2(b). A ballast mast was used with the lower leg to represent the mass of the upper leg. 


\subsection{Data processing}

For each simulation, stress was measured in a portion of the tibia consistent with its corresponding experiment. For Funk's experiment, stress was measured in a cross-section of the distal tibia (Funk et al., 2000). For McKay's experiments, stress was measured in a cross-section of the mid-tibia (Mckay, 2010). Therefore our approach attempts to mimic those measurements. Elements were selected at the location of interest and axial stress in those elements was plotted over time. The stress curves for all elements were averaged using the processing tools available in LS-DYNA. High frequency noise in the data necessitates the use of a low-pass filter, and node mass can also affect the necessary filter frequency for finite element models (Fasanella and Jackson, 2002). Stress was processed using an SAE filter with units of seconds, at a frequency of $180 \mathrm{~Hz}$, and using a nine point average (Fasanella and Jackson, 2002). The filtered stress was integrated across the cross-sectional area of the tibia to obtain forces over time according to equation (2).

$$
F_{z}=\int_{A} \sigma_{z z} d A
$$

In this equation, $\sigma_{z z}$ is the stress in the vertical direction, $A$ is the area of the tibia over which the stress was integrated, and $F_{z}$ is the resultant force.

\section{Additional considerations}

In addition to comparison of simulations of a lower extremity model to experimental data, some additional considerations were taken into account, such as extending the model to the full lower extremity, examining soft tissue properties, and determining the effect of a combat boot.

\subsection{Extension of results to full lower extremity}

When modelling biological systems, it is useful to consider a hierarchical modelling framework (Thacker et al., 2007; Kraft et al., 2012). Within such a framework, the components and sub-assemblies are critical to the system-level response. While the full (system-level) human body response is of interest, modelling at various levels of the anatomical hierarchy can provide different insights, and information gained at a given level can contribute to the fidelity of other levels. For this research, an assembly level model was considered. In replication of experimental lower extremity impact data, initial simulations were conducted with only the portion of the leg below the knee, and then extended to the full lower extremity, another assembly model. The lower leg geometry included flesh, cortical and trabecular tibia bone, fibula, cortical and trabecular calcaneus bone, and the remaining bones of the foot and ankle. The full lower extremity model additionally included the femur and pelvis. This anatomy is illustrated in Figure 1. The full lower extremity model was used for a simulation using the $10 \mathrm{~m} / \mathrm{s}$ loading conditions illustrated in Figure 2(b). In this simulation, the full extremity was free to move vertically, though the hip was constrained in other degrees of freedom. In the below knee case, a ballast mass was incorporated to represent the mass of the upper portion of the lower extremity, therefore no ballast mass was needed for the full lower extremity. The 
mid-tibia force results were collected and compared to the below-knee results to determine the suitability of extending the model. The comparison of the full lower extremity with the below-knee model was intended to gauge the consistency and accuracy of the results at both levels of modelling. Furthermore, because the 90-90-90 idealised posture may not be representative of all seated soldier positions, simulations should be conducted with a variety of leg positions. The full lower extremity model was repositioned using a surface editing software. Additional postures included a $120^{\circ}$ position, where the knee and ankle were bent to $120^{\circ}$, and a $60^{\circ}$ position, where the knee and ankle were bent to $60^{\circ}$. The $10 \mathrm{~m} / \mathrm{s}$ loading conditions were applied to these models with the full lower extremity free to move vertically. The von Mises stress was measured in the mid-tibia for these cases in addition to the 90-90-90 case. The three poses are illustrated in Figure 3.

Figure 3 Three different poses were compared in impact simulations (see online version for colours)
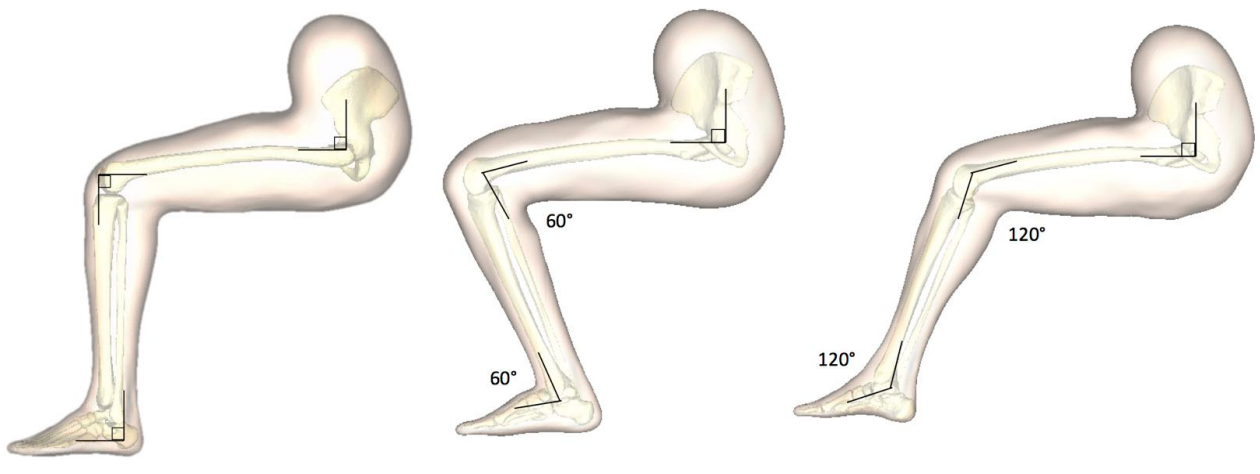

\subsection{Soft tissue parameters}

A wide range of hyperelastic coefficients for soft tissue can be found in literature, from as low as $0.12 \mathrm{kPa}$ (Untaroiu et al., 2005) to as high as $0.94 \mathrm{MPa}$ (Kraft et al., 2012). A study of in vivo soft tissue of amputees tested lower leg soft tissue at 7-11 locations at three rates on seven subjects and found a range of hyperelastic coefficients from $.01 \mathrm{kPa}-700 \mathrm{kPa}$ (Tönük and Silver-Thorn, 2003). Furthermore, while some models use hyperelastic material models (Lapeer et al., 2011; Cox et al., 2007), others models incorporate viscoelasticity (Gabler et al., 2014; Untaroiu et al., 2005). Due to the variation of human material properties found in literature, parametric studies regarding flesh material properties may offer insight into the effects of this variability on results. Preliminary investigations were conducted using the $10 \mathrm{~m} / \mathrm{s}$ loading conditions illustrated in Figure 2(b) with $C_{1}=C_{2}=1 \mathrm{kPa}, 10 \mathrm{kPa}$, and $100 \mathrm{kPa}$, which are all within the range of available values found in literature (Untaroiu et al., 2005; Kraft et al., 2012; Tönük and Silver-Thorn, 2003) to determine the difference caused by varying the soft tissue properties. A comparable sensitivity analysis for bone may be considered in the future, however the corridor of reported bone material properties shows fewer discrepancies than reported soft tissue parameters (Untaroiu et al., 2005; Kraft et al., 2012; Krone and Schuster, 2006). 


\subsection{Incorporation of a combat boot}

In real-world military scenarios, soldiers are outfitted with combat boots; therefore this type of personal protective device should be incorporated into modelling efforts. A combat boot model was obtained from a collection of professionally developed 3D models (TurboSquid, 2010) and modified using CAD software to fit the boot to the lower extremity model. The boot sole geometry was qualitatively compared to a standard issue army Reserve Officers' Training Corps (ROTC) combat boot. Comparative images are shown in Figure 4. A volume mesh was generated using ICEM CFD. The sole of the boot was added to the $10 \mathrm{~m} / \mathrm{s}$ loading model to better replicate a real-world scenario. The boot sole was modelled as hyperelastic rubber material using the material parameters for three different stiffness levels of polyurethane rubber as described by a study of finite element shoe sole models (Franciosa et al., 2013). As before, the mid-tibia force was measured. Fracture was also examined. The material parameters used for the boot sole are given in Table 4. The Mooney-Rivlin rubber material model defines the following strain energy density function (LSTC, 2015b):

$$
W=A\left(I_{1}-3\right)+B\left(I_{2}-3\right)+C\left(I_{3}^{-2}-1\right)+D\left(I_{3}-1\right)^{2}
$$

Here, $I_{1}, I_{2}$ and $I_{3}$ represent the right Cauchy-Green tensor invariants. The coefficients $C$ and $D$ are given by the following equation, where $v$ is Poisson's ratio and the linear elastic shear modulus is given by 2$) A+B)($ LSTC, 2015b):

$$
\begin{aligned}
& C=0.5 A \\
& D=\frac{A(5 v-2)+B(11 v-5)}{2(1-2 v)}
\end{aligned}
$$

Figure 4 The model of a combat boot sole was qualitatively compared to a standard issue army ROTC combat boot (see online version for colours)
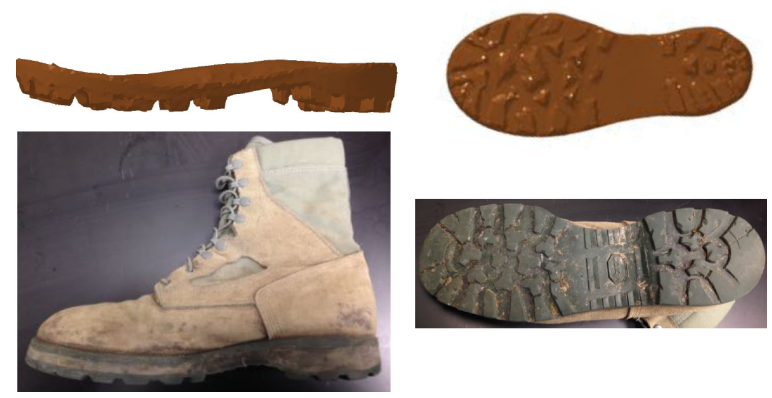

Table 4 Material properties used to model polyurethane rubber boot sole

\begin{tabular}{lcccc}
\hline & $\begin{array}{c}\text { Density }(\mathrm{kg} / \mathrm{m} 3) \\
\text { (Ramezani et al., } \\
\text { 2009) }\end{array}$ & $\begin{array}{c}\text { Poisson's Ratio } \\
\text { (Ramezani et al., } \\
\text { 2009) }\end{array}$ & $\begin{array}{c}\text { A (MPa) } \\
\text { (Franciosa et al., } \\
\text { 2013) }\end{array}$ & $\begin{array}{c}\text { B (MPa) } \\
\text { (Franciosa et al., } \\
\text { 2013) }\end{array}$ \\
\hline Soft & 2,000 & .499 & 0.969 & 0.314 \\
Medium & 2,000 & .499 & 1.265 & 0.416 \\
Hard & 2,000 & .499 & 1.325 & 0.314 \\
\hline
\end{tabular}




\subsection{Mesh dependence}

A mesh dependency study was completed at three mesh resolutions. The coarsest mesh included 168,768 elements ranging in size from 2 to $10 \mathrm{~mm}$ with an initial time step of $1.85 \mathrm{e}-7$ seconds, the medium coarse mesh included 1,754,856 elements from 1 to $4 \mathrm{~mm}$ and an initial time step of $4.09 \mathrm{e}-8 \mathrm{~s}$, the medium fine mesh included 3,409,805 elements from 0.5 to $3 \mathrm{~mm}$ and an initial time step of $3.77 \mathrm{e}-8 \mathrm{~s}$, and the finest mesh included $8,543,723$ elements from 0.5 to $2 \mathrm{~mm}$ with an initial time step of $1.38 \mathrm{e}-8 \mathrm{~s}$. Simulations were conducted with the $10 \mathrm{~m} / \mathrm{s}$ loading conditions illustrated in Figure 2. Failure criterion does not depend on element size.

\section{Results}

\section{1 'Low rate' case}

The results of the $5 \mathrm{~m} / \mathrm{s}$ simulations as compared to Funk's experimental data (Funk et al., 2000) are shown in Figure 5(a), along with the deformation of the foot at 5, 10, 15, 25,30 , and $34 \mathrm{~ms}$. The simulated results fall within the range of the experimental data. The magnitude of simulated forces matches experimental forces and the loading and unloading pattern agrees. As illustrated in Figure 5(b), deformation of the soft tissue has just begun by $10 \mathrm{~ms}$, and by $20 \mathrm{~ms}$ the bones of the foot have shown a large amount of articulation and the tarsals have begun to spread and lift off of the plate. This tarsal displacement continues to increase for the remainder of the simulation. Some bowing is seen in the tibia.

Figure 5 (a) Simulated results for lower leg impact at $5 \mathrm{~m} / \mathrm{s}$ as compared to experimental data (b) Deformation of the lower leg over the course of the simulation (see online version for colours)

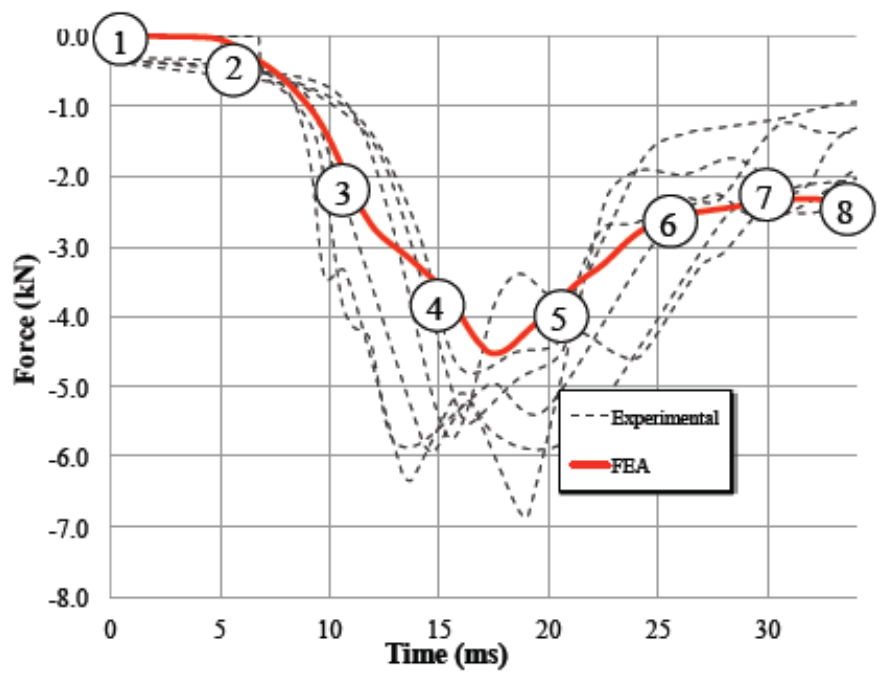

(a) 
Figure 5 (a) Simulated results for lower leg impact at $5 \mathrm{~m} / \mathrm{s}$ as compared to experimental data (b) Deformation of the lower leg over the course of the simulation (continued) (see online version for colours)
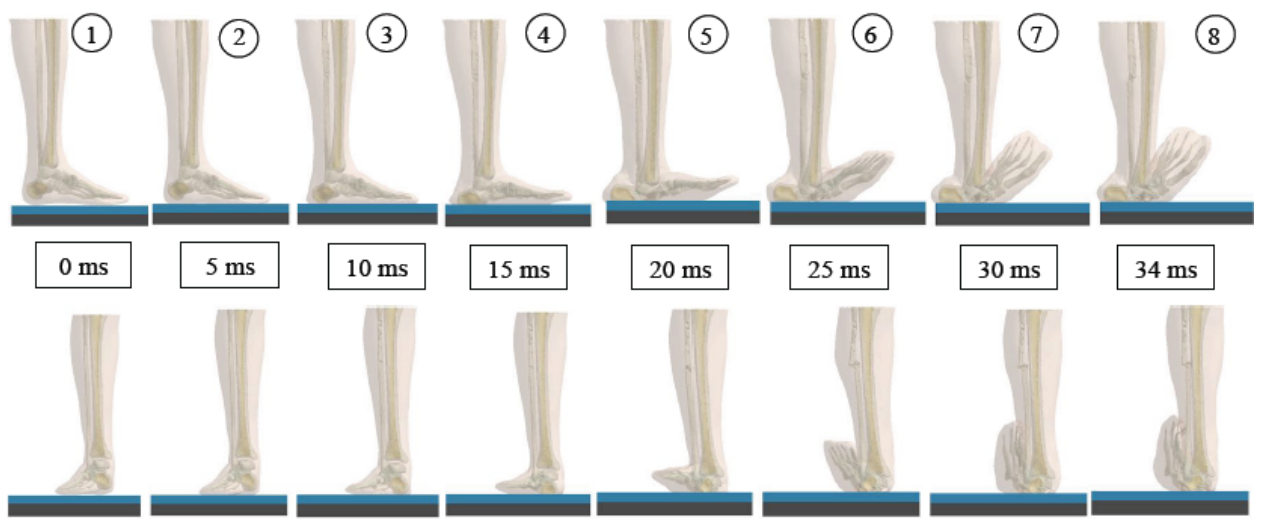

(b)

Source: Funk et al. (2000)

\section{2 'High rate' case}

High rate simulations are compared to McKay's data for $10 \mathrm{~m} / \mathrm{s}$ and $12 \mathrm{~m} / \mathrm{s}$ in Figure 6(a) and 6(b) respectively (Mckay, 2010). Here, too, the simulated results are very comparable to the experimental data in both force magnitude and shape. In the $10 \mathrm{~m} / \mathrm{s}$ simulation case, Figure 6(a), between $1 \mathrm{~ms}$, when loading begins, and $3 \mathrm{~ms}$, the soft tissue at the bottom of the foot is deforming and the tarsals begin to lift away from the plate. At $3 \mathrm{~ms}$, the soft tissue has compressed beneath the bones of the foot and the plate begins to flatten the foot. Between $3 \mathrm{~ms}$ and $4 \mathrm{~ms}$, the flattening of the foot causes the bones of the foot come into contact with each other. Around $4 \mathrm{~ms}$, contact between the talus and the tibia causes the tibia to begin to bow. By this point, fracture can be seen at the interfaces of the cuboid, navicular, and cuneiform bones and between the talus and tibia, as well as where the calcaneus is in contact with the plate. By $5 \mathrm{~ms}$, the proximal fibula and distal tibia begin to show damage, which continues to increase in severity until around $6 \mathrm{~ms}$. Increasing foot articulation and tibia bowing are seen until around $9 \mathrm{~ms}$. By $9 \mathrm{~ms}$, loading has ceased. However, inertia continues to deform the bones and soft tissue for the remainder of the simulation. Around $11 \mathrm{~ms}$ the distal fibula fractures. The same pattern of deformation and fracture is seen in the $12 \mathrm{~m} / \mathrm{s}$ simulation, Figure $6(\mathrm{~b})$. However, the extent of the deformation is greater. In both cases, the lower leg does not exhibit axial displacement until approximately $5 \mathrm{~ms}$, after which time the leg begins to move vertically until around $10 \mathrm{~ms}$, after which time displacement begins to decrease. Figure 7 shows a closer view of the talus and calcaneus during loading. Initially, the calcaneus is tilted posteriorly as the force of the loading plate flattens the foot. After the foot has flattened, the calcaneus locks with the talus and is translated axially. 
Figure 6 (a) Simulated results for lower leg impact at $10 \mathrm{~m} / \mathrm{s}$ as compared to experimental data (b) Simulated results for lower leg impact at $12 \mathrm{~m} / \mathrm{s}$ as compared to experimental data (see online version for colours)

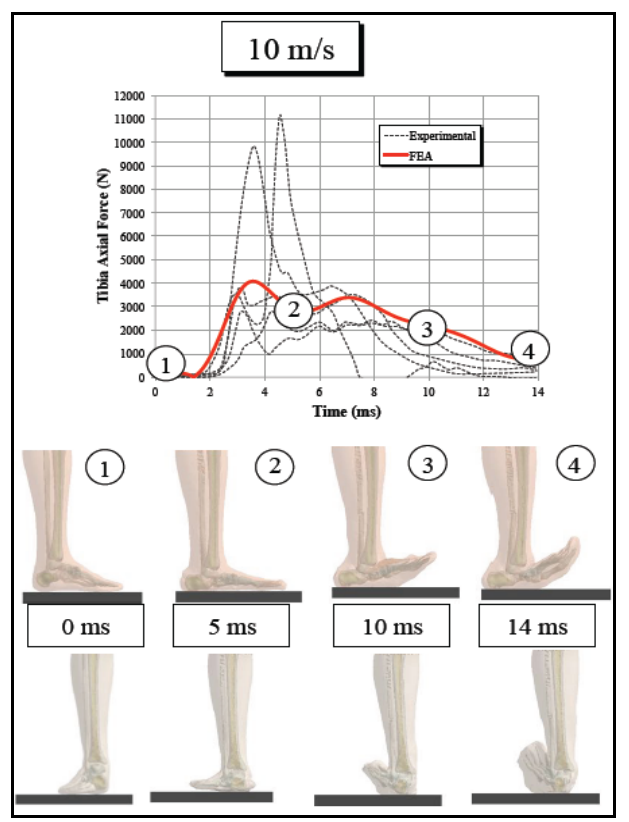

(a)

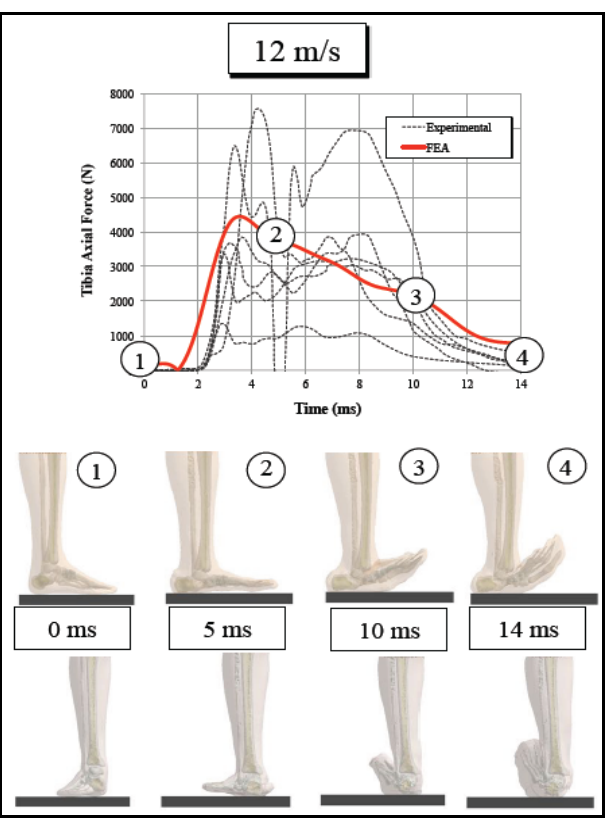

(b)

Source: Mckay (2010)

Figure 7 Initially, the calcaneus is tilted posteriorly as the force of the loading plate flattens the foot, after the foot has flattened, the calcaneus locks with the talus and is translated axially
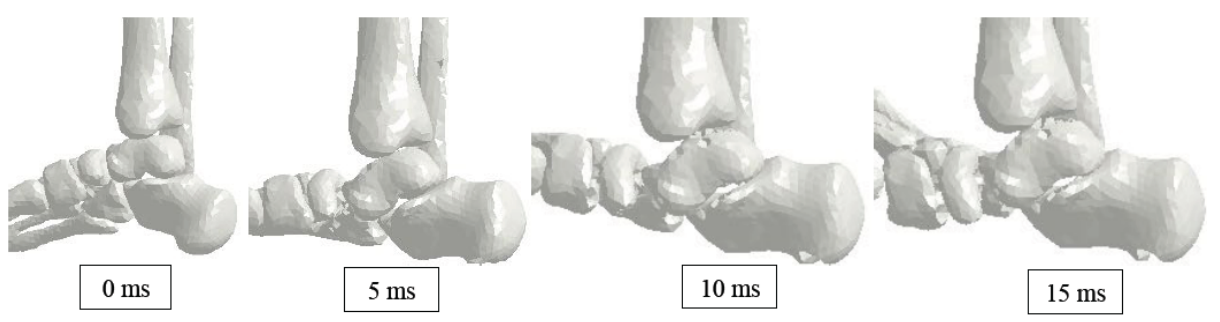

At $10 \mathrm{~m} / \mathrm{s}$ and $12 \mathrm{~m} / \mathrm{s}$, fracture was seen over the course of the simulation. Figure 8 shows the simulated fracture patterns and the percent change in bone volume over time. In both cases, fracture is concentrated especially in the calcaneus, fibula, and tibia. The interfaces of the cuboid, navicular, and cuneiform bones of the foot also show fracture at both loading rates. At $10 \mathrm{~m} / \mathrm{s}$ and $12 \mathrm{~m} / \mathrm{s}$, McKay noted skeletal injuries in the calcaneus, tibia, talus, fibula, and tarsometatarsal. He also notes the occurrence of articular fractures, which supports the presence of simulated injuries at bone interfaces (Mckay, 2010). These fracture locations are also consistent with reported fracture locations in an UBB injury review which notes talus, tibia, calcaneus, and malleolar fractures (Pintar, 2012), which provides encouragement that these simulations correlate with UBB scenarios. 
Figure 8 Fracture patterns seen following the $10 \mathrm{~m} / \mathrm{s}$ and $12 \mathrm{~m} / \mathrm{s}$ simulations are shown alongside graphs of percent change in bone volume over time for all bones included in the simulation (see online version for colours)
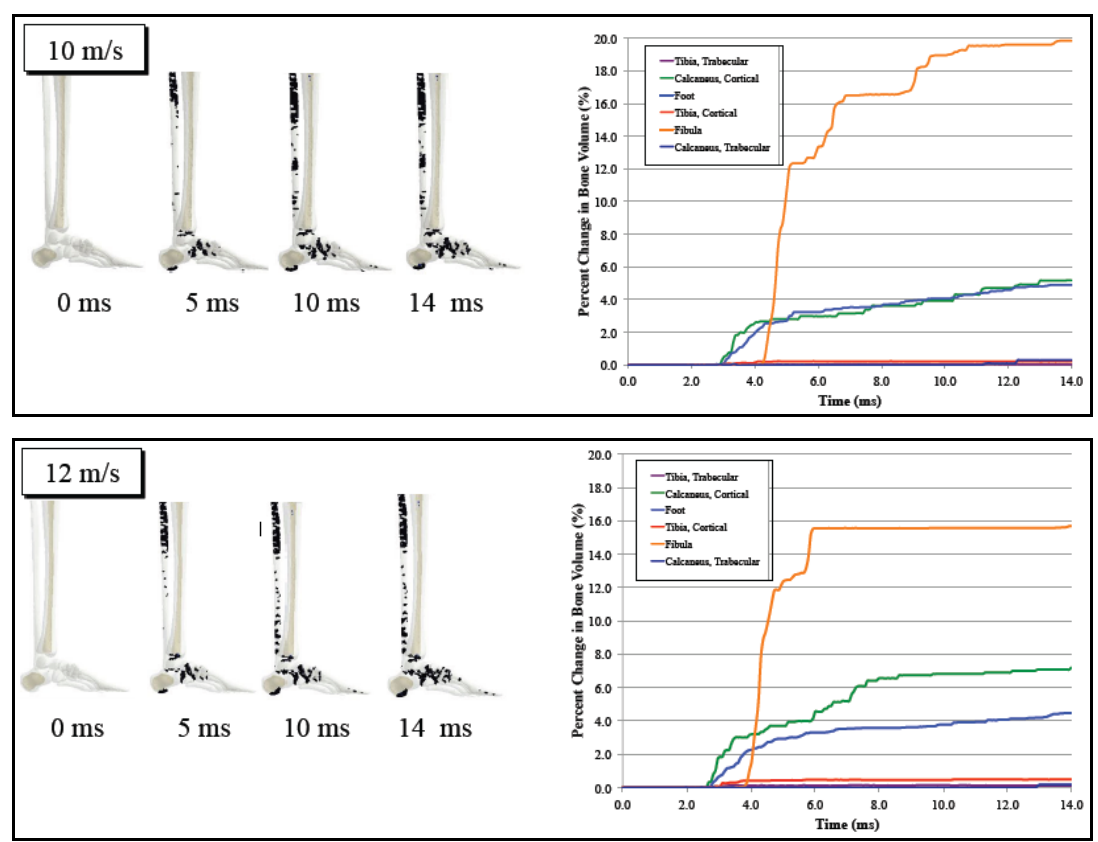

Figure 9 Example AIS injury ratings for resultant simulated injuries at $10 \mathrm{~m} / \mathrm{s}$ applied loading (see online version for colours)

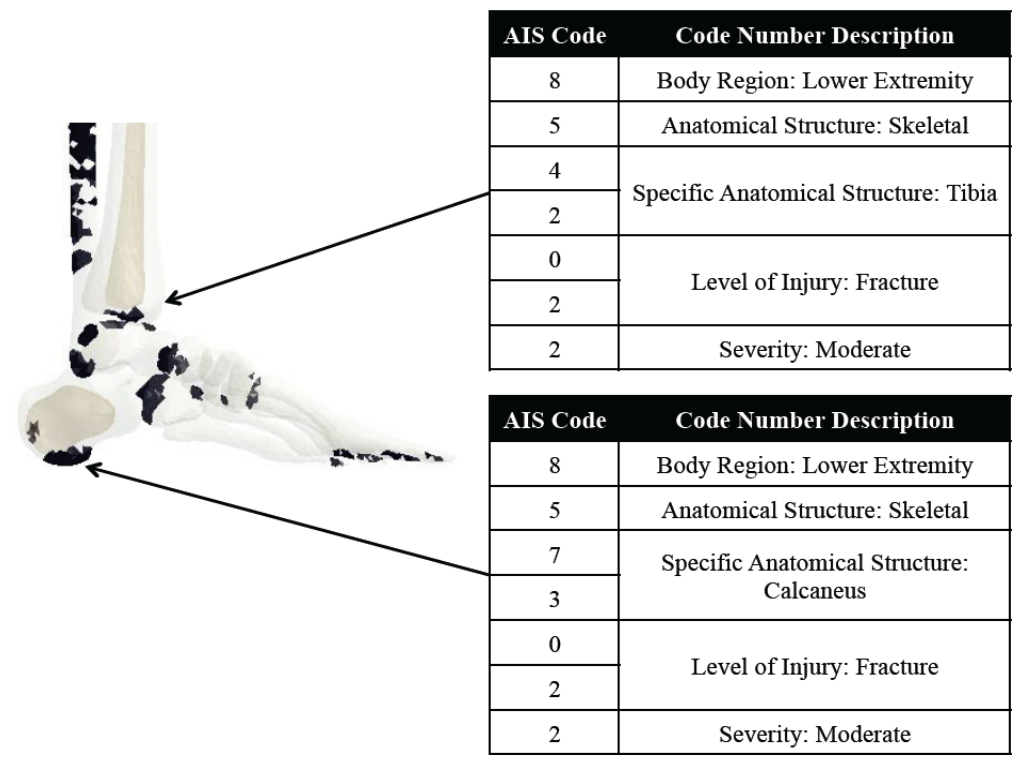

One of the ultimate goals of modelling a variety of injury inducing scenarios is to develop a framework for rating and classifying injuries. We have begun to examine the 
process of determining AIS ratings for simulated injuries. The AIS assigns injuries a seven digit code based on body region, type and location of anatomic structure, level of injury, and severity (Lesko et al., 2010). We believe that this may be a way to communicate our results more effectively with physicians and protective equipment designers. Being able to classify predicted injuries would contribute to the prevention and treatment of combat zone injuries. Example injury ratings are shown in Figure 9.

Figure 10 (a) Comparison between full leg and lower leg results show good agreement at both levels (b) Additional seated soldier positions may affect results and should be considered in future work (see online version for colours)
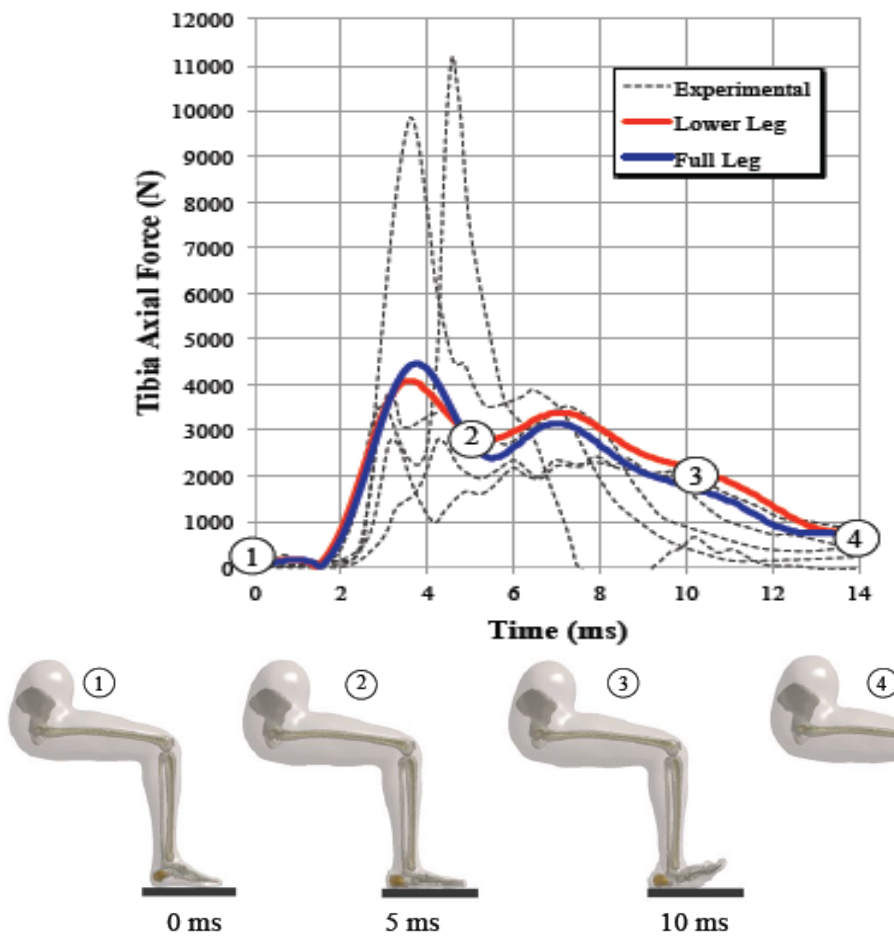

(2)

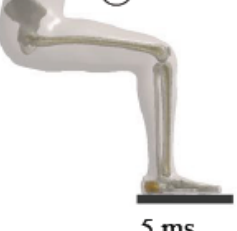

(3)

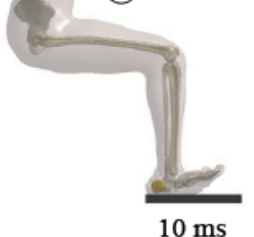

(a)
(4)

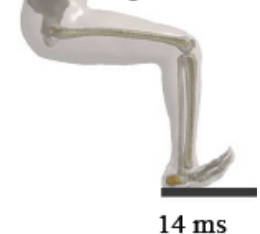

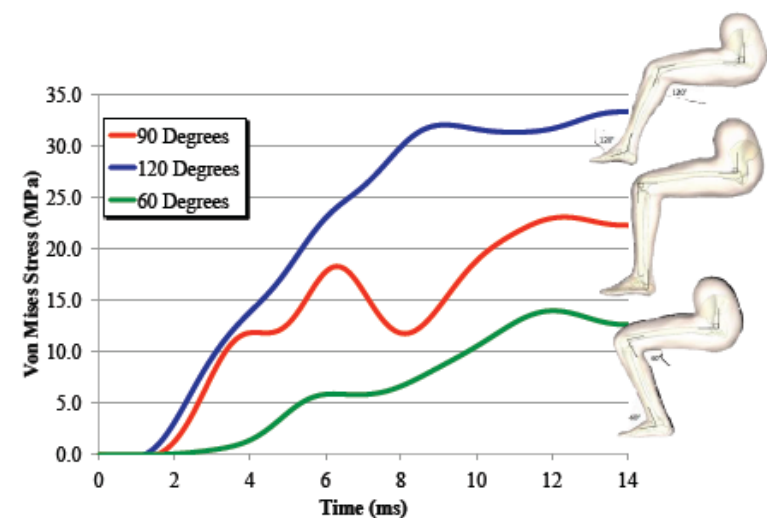

(b) 
The $10 \mathrm{~m} / \mathrm{s}$ loading conditions (Mckay, 2010) illustrated in Figure 2 were applied to an additional full lower extremity model incorporating the femur and hip. The model was free to move vertically. Results are shown in Figure 10(a). The agreement between the behaviour of the lower leg and full leg model gives confidence in the accuracy of both models and supports the use of a hierarchical approach. Because the 90-90-90 idealised posture may not be representative of all seated soldier positions, simulations should be conducted with a variety of leg positions. A preliminary study of von Mises stress in the tibia at $10 \mathrm{~m} / \mathrm{s}$ loading conditions indicates that leg posture may impact extremity response under loading, as shown in Figure 10(b).

Preliminary investigations regarding the sensitivity of the simulation results to soft tissue parameters were conducted using the $10 \mathrm{~m} / \mathrm{s}$ loading conditions with $\mathrm{C}_{1}=\mathrm{C}_{2}=1 \mathrm{kPa}$, $10 \mathrm{kPa}$, and $100 \mathrm{kPa}$, which are all within the range of available values found in literature (Kraft et al., 2012; Tönük and Silver-Thorn, 2003; Untaroiu et al., 2005). The results reveal the significant difference caused by varying the soft tissue properties. This investigatory result, shown in Figure 11, indicates a need for further work on clarification of material properties within the biomechanics community.

Figure 11 Soft tissue material properties cause significant variation in simulation results and should be further studied (see online version for colours)
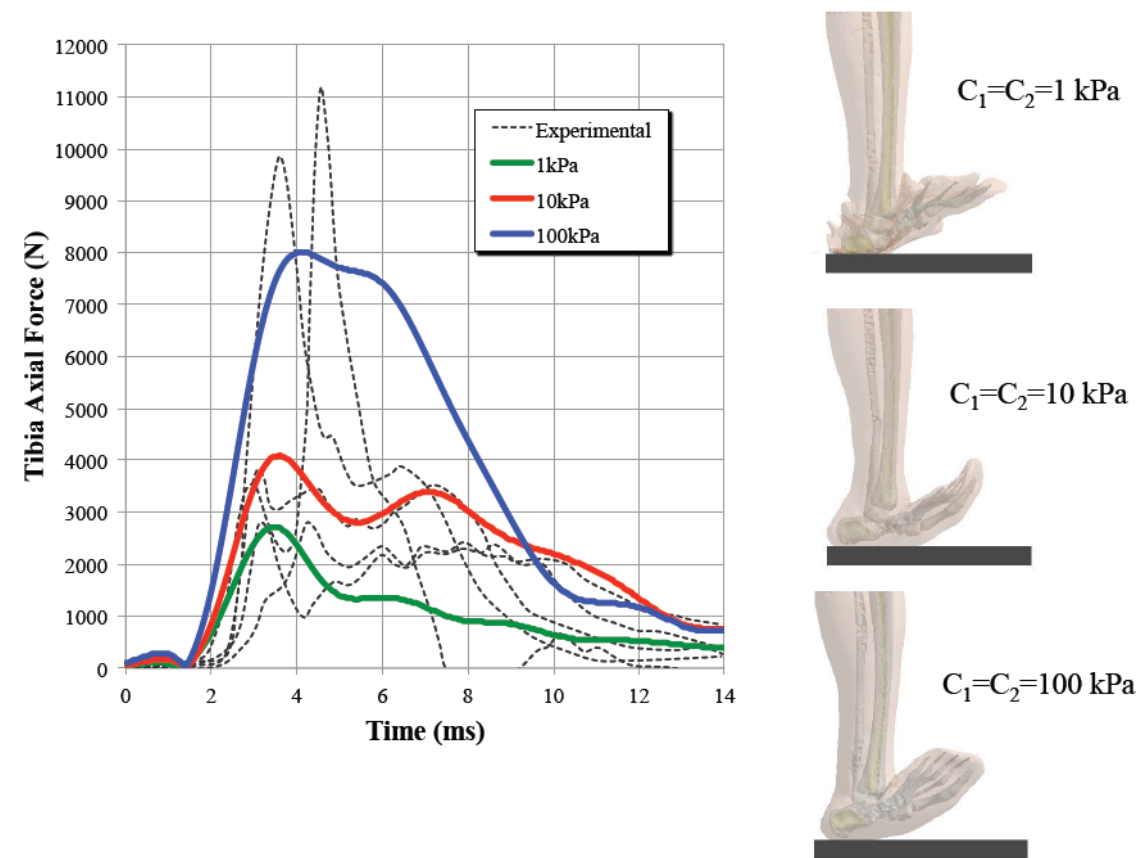

The sole of a boot was added to the $10 \mathrm{~m} / \mathrm{s}$ loading model to better replicate a real-world scenario and modelled as a hyperelastic material with material properties given in Table 3. Early results indicate that the presence of a boot may mitigate the extent of fracture. This is especially evident in the calcaneus, where significant fracture with no boot sole is reduced to very minimal fracture with a boot sole. The effect is also seen in the fibula and the tibia. The softer boot sole shows the greatest reduction of fracture 
severity. The boot sole also delays and reduces the peak force in the tibia. However, the boot sole does limit the unloading of the tibia over time. The stiffer the boot sole material, the less the tibia unloads by the end of the simulation. This is illustrated in Figure 12. Future work should seek to compare a variety of boot sole materials and boot leather tensions.

Figure 12 (a) The deformation of the boot sole over the simulation is shown for the medium sole case (b) The boot sole also reduces the peak force in the tibia (c) Early results indicate that the presence of a boot may slightly mitigate the extent of fracture in the calcaneus, tibia, and fibula (see online version for colours)

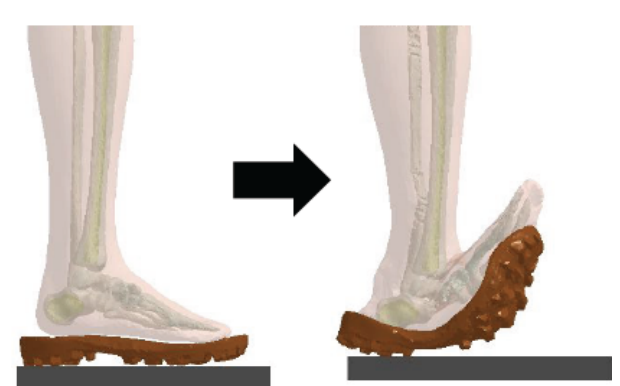

(a)

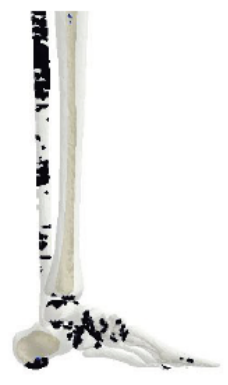

No Boot

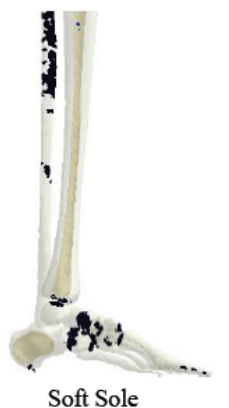

(c)

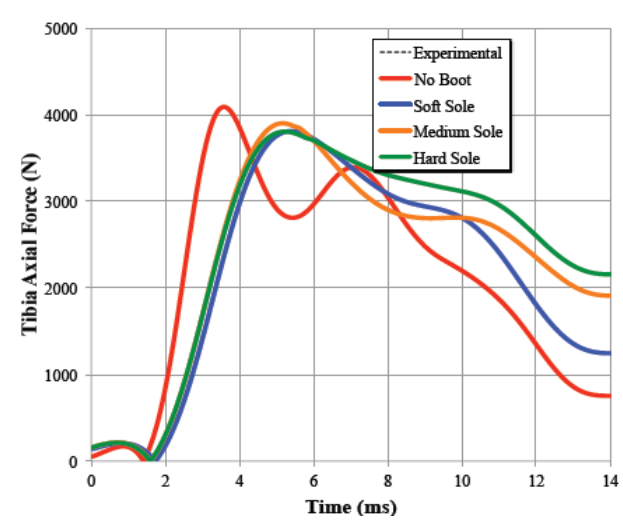

(b)
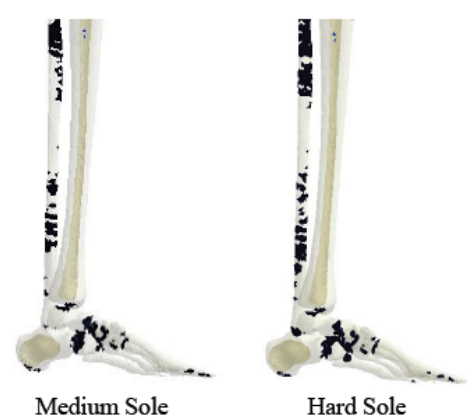

A mesh dependency study was completed at three mesh resolutions. A comparison of the four meshes is shown in Figure 13(a). Figure 13(b) shows simulation results for the primary loading phase of these simulations. The results appear to converge at the 3.5 million element mesh, but at added computational cost. The finest mesh required three weeks on eight processors to complete the primary loading phase illustrated in Figure 13. The coarsest required only three hours for the same simulation period. These converged results are lower in magnitude than the coarser simulations, though still within the experimental corridor. This indicates that element softening may occur at larger numbers of elements. Mesh convergence will continue to be studied in ongoing work. 
Figure 13 (a) A mesh dependency study was completed at three mesh resolutions, the coarsest mesh (1) included 168,768 elements, the medium coarse mesh (2) included 1,754,856 elements, the medium fine mesh (3) included 3,409,805 elements, and the finest mesh (4) included 8,543,723 elements (b) The results appear to converge at the 3.5 million element mesh (see online version for colours)

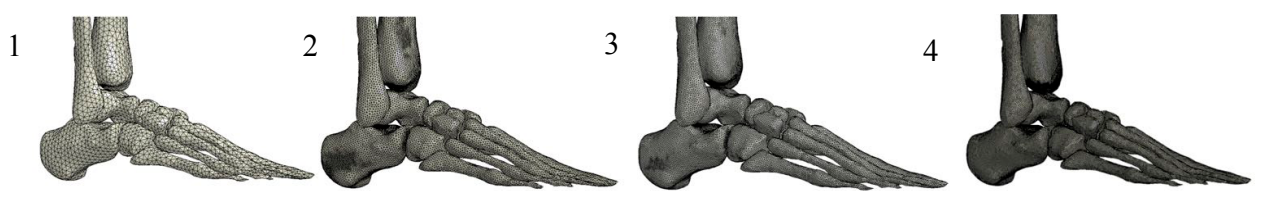

(a)

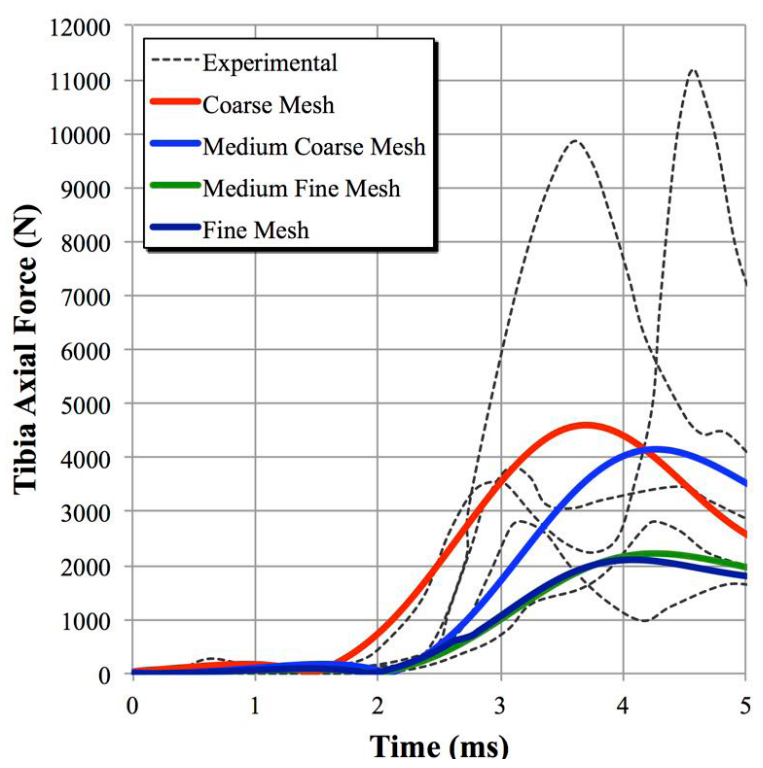

(b)

\section{Discussion}

As illustrated in Figure 8, fracture occurs in the lower extremity over the course of higher rate simulations. Damage is concentrated especially in the calcaneus, fibula, at the interfaces of the cuboid, navicular, and cuneiform bones of the foot, and at the interface between the talus and the tibia. No significant difference is seen in fracture locations between the $10 \mathrm{~m} / \mathrm{s}$ and $12 \mathrm{~m} / \mathrm{s}$. At both loading rates, the percent volume of damaged bone gradually and consistently increases over the simulation for the cortical calcaneus and the remaining bones of the foot. The cortical tibia, trabecular tibia, and trabecular calcaneus show relatively small amounts of damage. The fibula is the most damaged bone at both loading rates. In the cortical tibia and cortical calcaneus, the extent of fracture is greater in the $12 \mathrm{~m} / \mathrm{s}$ loading case than in $10 \mathrm{~m} / \mathrm{s}$ case. The extent of damage in the foot, trabecular tibia, and trabecular calcaneus is similar in both loading cases. It is 
interesting to note that the extent of fibula damage is greater at $10 \mathrm{~m} / \mathrm{s}$ than at $12 \mathrm{~m} / \mathrm{s}$. As can be seen in the graph in Figure 8, at $10 \mathrm{~m} / \mathrm{s}$, percent volume of damaged bone in the fibula increases to $13 \%$ at $4 \mathrm{~ms}$, then gradually increases to $17 \%$ at around $7 \mathrm{~ms}$, and continues to gradually increase over the remainder of the simulation, ending with a final damaged volume of $20 \%$. At $12 \mathrm{~m} / \mathrm{s}$, like at $10 \mathrm{~m} / \mathrm{s}$, percent volume of damaged bone in the fibula increases to $13 \%$ at $4 \mathrm{~ms}$. However, at $12 \mathrm{~m} / \mathrm{s}$, the damaged fibula volume more sharply spikes to $15 \%$ at $6 \mathrm{~ms}$, and the damage remains constant for the remainder of the simulation. The sharper and earlier increase in fibula damage at $12 \mathrm{~m} / \mathrm{s}$ may account for the difference between $10 \mathrm{~m} / \mathrm{s}$ and $12 \mathrm{~m} / \mathrm{s}$, as a possible explanation is that the more sudden fibula fracture earlier in the simulation at $12 \mathrm{~m} / \mathrm{s}$ renders the fibula unable to carry the load that causes the fracture later in the $10 \mathrm{~m} / \mathrm{s}$ simulation.

In a review of 500 warriors wounded in action who were exposed to under body blasts, almost $200(40 \%)$ had foot and ankle injures. Furthermore, the injury review showed 57 instances of talus fracture, 56 instances of tibia fracture, and at least 100 calcaneus fractures. Malleolar fractures were also noted (Pintar, 2012). The patterns of simulated injury correlate with these statistics, as fracture occurred in the calcaneus, tibia, talus, and fibula. The simulated injuries are also consistent with reported skeletal injuries during experiments by McKay (2010). At $10 \mathrm{~m} / \mathrm{s}$ and $12 \mathrm{~m} / \mathrm{s}$, McKay noted skeletal injuries in the calcaneus, tibia, talus, fibula, and tarsometatarsal. He also notes the occurrence of articular fractures, which supports the presence of simulated injuries at bone interfaces (Mckay, 2010).

A mesh dependency study was completed at three mesh resolutions. The primary mesh used, according to this study, did not reach a converged solution. However, using a converged mesh solution required significant additional computational cost. The finest mesh required three weeks on eight processors to complete the primary loading phase illustrated in Figure 13. The coarsest required only three hours for the same simulation period. So, in order to complete a variety of simulations with varying loading conditions and parameters, such a fine mesh is infeasible. We believe that a coarser mesh is sufficient for impact force prediction and prediction of general fracture locations. A finer mesh may be necessary for more intricate modelling of fracture networks. This mesh convergence will continue to be studied in future work.

While good results are seen in the agreement between experimental and simulated results, there are some limitations to the work presented. Rate dependent effects and viscoelasticity were not considered. The model is also limited in its anatomy. Ligaments, tendons, and articular cartilage are not included. Additionally, the metatarsals are fused to increase model stability. However, this may reduce the ability of the foot to articulate during the simulation. These limitations will be improved upon in future work. The experimental data available may be a limiting factor. For experiments conducted at 10 $\mathrm{m} / \mathrm{s}$ and $12 \mathrm{~m} / \mathrm{s}$, a portion of the tibia was removed and replaced with a load cell (Mckay, 2010). This may compromise data. In both experimental cases, data is only reported at one cross-section of the tibia, and thus the models are validated against this tibia force data. However, it is possible that the model and experimental behaviour may deviate in other aspects. Finally, with any post-mortem human subject experiment, it should be kept in mind that human variability is extensive, and post-mortem human results may not be fully representative of in vivo response. 


\section{Conclusions}

In an effort to contribute to the field of human biomechanical modelling of UBB scenarios, an attempt was undertaken to validate a lower leg finite element model against experimental data for axial loading at $5 \mathrm{~m} / \mathrm{s}, 10 \mathrm{~m} / \mathrm{s}$, and $12 \mathrm{~m} / \mathrm{s}$. Simulations were conducted with loading and boundary conditions which replicated the post-mortem human studies completed at each loading rate. Following completed simulations, stress was measured at a cross-section of the tibia in accordance with the location experimentally measured. The measured stress was integrated across the area to obtain the forces. The resultant simulated forces were compared to experimental results. Results of these simulations fall within the range of available experimental data, which gives confidence that this model represents advancement in lower extremity modelling capabilities. Additionally, where fracture was modelled, fracture locations were consistent with common reported blast injury sites. This work represents a positive advancement towards the development of lower extremity models at a variety of loading rates.

\section{Acknowledgements}

This work was partially funded by a sub-contract from CFDRC for the US Army MRMC SBIR topic DHPI3-010 physics and physiology based human body model of blast injury and protection. This work was supported in part through instrumentation funded by the National Science Foundation through grant OCI-0821527.

\section{References}

Alvarez, J. (2011) 'Epidemiology of blast injuries in current operations', in A Survey of Blast Injury Across the Full Landscape of Military Science, NATO Science and Technology Organization, Keynote KN1, Halifax, Canada.

Arepally, S. et al. (2008) Application of Mathematical Modeling in Potentially Survivable Blast Threats in Military Vehicles [online] http://oai.dtic.mil/oai/oai?verb=getRecord\&metadata Prefix $=$ html\&identifier $=$ ADA496843 (accessed 6 November 2013).

Bertucci, R., Liao, J. and Williams, L. (2011) 'Development of a lower extremity model for finite element analysis', Proceedings of the ASME 2011 Summer Bioengineering Conference, Farmington, PA, ASME, pp.1-2 [online] http://proceedings.asmedigitalcollection.asme.org/ data/Conferences/ASMEP/75299/1035_1.pdf (accessed 3 February 2015).

Blender Foundation (1995) 'Blender', Free and Open 3D Creation Software [online] http://www.blender.org/ (accessed 1 December 2015).

Bonet, J. and Burton, A.J. (1998) 'A simple average nodal pressure tetrahedral element for incompressible and nearly incompressible dynamic explicit applications', Communications in Numerical Methods in Engineering, Vol. 14, No. 5, pp.437-449.

Chancey, C. et al. (2011) Program for Warrior Injury Assessment Manikin (WIAMan) [online] https://blastinjuryresearch.amedd.army.mil/docs/WIAMan_Project_Plan_Industry_ Day_V3.pdf (accessed 7 October 2014).

Christopher, J.J. (2012) U.Va-CAB Underbody Blast Overview and WIAman Research, Dayton, O.H [online] http://safeassn.info/wbc/assets/images/UVA-CAB UBB Overview and WIAMan Research_forSAFEdistribution.pdf (accessed 16 February 2015). 
Cox, S.L., Mithraratne, K. and Smith, N.P. (2007) 'An anatomically based finite element model of the lower limbs in the seated posture', Annual International Conference of the IEEE Engineering in Medicine and Biology Society, IEEE Engineering in Medicine and Biology Society, pp.6327-6330.

Dow Automotive (2009) Finite Element Analyses with IMPAXX Energy Absorbing Foams in Headliner Applications: Modeling Instructions and Material Models for Use in FMVSS201U Head Impact Simulations [online] http://msdssearch.dow.com/PublishedLiteratureDOWCOM/ dh_030b/0901b8038030b1d4.p df? filepath=automotive/pdfs/noreg/299-51549.pdf\& fromPage $=$ GetDoc (accessed 4 February 2015).

Erhard, T. (2011) Review of Solid Element Formulations in LS-DYNA, Stuttgart, Germany [online] http://www.dynamore.de/de/download/papers/forum11/entwicklerforum-2011/erhart.pdf (accessed 28 September 2014).

Fasanella, E.L. and Jackson, K.E. (2002) Best Practices for Crash Modeling and Simulation, NASA/TM-2002-211944 ARL-TR-2849, NASA Langley Research Center, Hampton, VA.

Franciosa, P. et al. (2013) 'Improving comfort of shoe sole through experiments based on CADFEM modeling', Medical Engineering and Physics, Vol. 35, No. 1, pp.36-46.

Funk, J.R. et al. (2000) The Role of Axial Loading in Malleolar Fractures, SAE Technical Paper Series, No. 724.

Gabler, L.F., Panzer, M.B. and Salzar, R.S. (2014) 'High-rate mechanical properties of human heel pad for simulation of a blast loading condition', IRC-14-87 IRCOBI Conference 2014 [online] http://www.ircobi.org/downloads/irc14/pdf_files/87.pdf (accessed 7 October 2014).

Gayzik, F.S. et al. (2011) 'Development of the Global Human Body Models Consortium mid-sized male full body model', Injury Biomechanics Research [online] http://wwwnrd.nhtsa.dot.gov/ pdf/BIO/Proceedings/2011_39/39-12.pdf (accessed 7 October 2014).

Glozman, T. and Azhari, H. (2010) 'A method for characterization of tissue elastic properties combining ultrasonic computed tomography with elastography', Journal of Ultrasound in Medicine!: Official Journal of the American Institute of Ultrasound in Medicine, Vol. 29, No. 3, pp.387-398.

Gordon, C.C. et al. (1989) 1988 Anthropometric Survey of U.S. Army Personnel: Pilot Summary Statistics [online] http://stinet.dtic.mil/cgibin/ GetTRDoc?AD=ADA241952\&Location= U2\&doc=GetTRDoc.pdf (accessed 1 December 2014).

Henderson, K.A. et al. (2013) 'Biomechanical response of the lower leg under high rate loading', IRC-13-24 IRCOBI Conference 2013, pp.145-157.

Hendriks, F.M. et al. (2003) 'A numerical-experimental method to characterize the non-linear mechanical behaviour of human skin', Skin Research and Technology, Vol. 9, No. 3, pp.274-283 [online] http://doi.wiley.com/10.1034/j.1600-0846.2003.00019.x (accessed 13 October 2014).

Kraft, R.H. et al. (2008) 'Computational micromechanics of dynamic compressive loading of a brittle polycrystalline material using a distribution of grain boundary properties', Journal of the Mechanics and Physics of Solids, Vol. 56, No. 8, pp.2618-2641 [online] $\mathrm{http}$ ://linkinghub.elsevier.com/retrieve/pii/S0022509608000549 (accessed 31 January 2014).

Kraft, R.H., Lynch, M.L. and Vogel III, E.W. (2012) 'Computational failure modeling of lower extremities', NATO HFM-207 Symposium, Aberdeen Proving Ground, Maryland, ARLRP-346 [online] http://www.dtic.mil/cgi-bin/GetTRDoc?AD=ADA562360 (accessed 1 February 2015).

Krone, R. and Schuster, P. (2006) An Investigation on the Importance of Material Anisotropy in Finite-Element Modeling of the Human Femur [online] http://www.sae.org/technical/ papers/2006-01-0064 (accessed 7 October 2014).

Kurtaran, H., Buyuk, M. and Eskandarian, A. (2003) 'Ballistic impact simulation of GT model vehicle door using finite element method', Theoretical and Applied Fracture Mechanics, Vol. 40, No. 2, pp.113-121. 
Lapeer, R.J., Gasson, P.D. and Karri, V. (2011) 'A hyperelastic finite-element model of human skin for interactive real-time surgical simulation', IEEE Transactions on Bio-Medical Engineering, Vol. 58, No. 4, pp.1013-22 [online] http://www.ncbi.nlm.nih.gov/pubmed/20172812 (accessed 13 October 2014).

Lee, S-H., Sifakis, E. and Terzopoulos, D. (2009) 'Comprehensive biomechanical modeling and simulation of the upper body', ACM Transactions on Graphics, Vol. 28, No. 4, pp.1-17 [online] http://portal.acm.org/citation.cfm?doid=1559755.1559756 (accessed 13 October 2014).

Lesko, M.M. et al. (2010) 'Using abbreviated injury scale (AIS) codes to classify computed tomography (CT) features in the Marshall system', BMC Medical Research Methodology, Vol. 10, No. 1, p.72.

LSTC (2015a) LS-DYNA Keyword User's Manual Volume II [online] http://ftp.lstc.com/ anonymous/outgoing/jday/manuals/DRAFT_Vol_II.pdf (accessed 13 January 2015).

LSTC (2015b) LS-DYNA Theory Manual, p.15 [online] http://ftp.lstc.com/anonymous/outgoing/ jday/manuals/DRAFT_Theory.pdf (accessed 13 January 2015).

Majumder, S., Roychowdhury, A. and Pal, S. (2007) 'Simulation of hip fracture in sideways fall using a 3D finite element model of pelvis-femur-soft tissue complex with simplified representation of whole body', Medical Engineering \& Physics, Vol. 29, No. 10, pp.1167-1178 [online] http://www.ncbi.nlm.nih.gov/pubmed/17270483 (accessed 13 October 2014).

Mckay, B.J. (2010) Development of Lower Extremity Injury Criteria and Biomechanical Surrogate to Evaluate Military Vehicle Occupant Injury During an Explosive Blast Event, PhD Thesis, Wayne State University [online] http://digitalcommons.wayne.edu/cgi/viewcontent.cgi?article $=1145 \&$ context $=$ oa_dissertations (accessed 13 September 2014).

McKay, B.J. and Bir, C.A. (2009) 'Lower extremity injury criteria for evaluating military vehicle occupant injury in underbelly blast events', Stapp Car Crash Journal, Vol. 53, No. 1, pp.229-249.

Mitsuhashi, N. et al. (2009) 'BodyParts3D: 3D structure database for anatomical concepts', Nucleic Acids Research, Vol. 37, No. 1, pp.D782-D785.

Nilakantan, G. and Tabiei, A. (2009) 'Computational assessment of occupant injury caused by mine blasts underneath infantry vehicles', International Journal of Vehicle Structures and Systems, Vol. 1, Nos. 1-3, pp.50-58.

Pintar, F.A. (2012) Biomedical Analyses, Tolerance, and Mitigation of Acute and Chronic Trauma, Milwaukee, WI [online] http://oai.dtic.mil/oai/oai?verb=getRecord\&metadataPrefix=html\& identifier $=$ ADA590473 (accessed 24 September 2014).

Qiu, T.X. et al. (2011) 'Finite element modeling of a 3D coupled foot-boot model', Medical Engineering and Physics, Vol. 33, No. 10, pp.1228-1233.

Ramasamy, A., Newell, N. and Masouros, S. (2014) 'From the battlefield to the laboratory: the use of clinical data analysis in developing models of lower limb blast injury', Journal of the Royal Army Medical Corps, Vol. 160, No. 2, pp.117-120.

Ramezani, M., Ripin, Z.M. and Ahmad, R. (2009) 'Computer aided modelling of friction in rubberpad forming process', Journal of Materials Processing Technology, Vol. 209, No. 10, pp.4925-4934.

Song, J-H., Wang, H. and Belytschko, T. (2008) 'A comparative study on finite element methods for dynamic fracture', Computational Mechanics, Vol. 42, No. 2, pp.239-250.

Suresh, M. and Zhu, F. (2012) Finite Element Evaluation of Human Body Response to Vertical Impulse Loading [online] http://blucherproceedings.com.br/pdf/ mechanicalengineeringproceedings/wccm/18555.pdf (accessed 7 October 2014).

Thacker, B.H., Francis, W.L. and Nicolella, D.P. (2007) 'Model validation and uncertainty quantification applied to cervical spine injury assessment', in Computational Uncertainty in Military Vehicle Design, pp.26-30, Neuilly-sur-Seine, France. 
Timmel, M. et al. (2007) 'A finite element model for impact simulation with laminated glass', International Journal of Impact Engineering, Vol. 34, No. 8, pp.1465-1478.

Tönük, E. and Silver-Thorn, M.B. (2003) 'Nonlinear elastic material property estimation of lower extremity residual limb tissues', IEEE Transactions on Neural Systems and Rehabilitation Engineering!: A Publication of the IEEE Engineering in Medicine and Biology Society, Vol. 11, No. 1, pp.43-53 [online] http://www.ncbi.nlm.nih.gov/pubmed/12797725 (accessed 30 September 2014).

TurboSquid (2010) TurboSquid [online] http://www.turbosquid.com/FullPreview/Index.cfm/ ID/517463 (accessed 2 February 2015).

Untaroiu, C. and Shin, J. (2013) 'Biomechanical and injury response of human foot and ankle under complex loading', Journal of Biomechanical Engineering, October, Vol. 135, pp.1-8 [online] http://www.ncbi.nlm.nih.gov/pubmed/23897434 (accessed 26 February 2014).

Untaroiu, C. et al. (2005) 'A finite element model of the lower limb for simulating pedestrian impacts', Stapp Car Crash Journal, Vol. 49, No. 1, pp.157-181.

\section{Appendix}

Stress-strain curve used for modelling of foam pad (Dow Automotive, 2009):

\begin{tabular}{|c|c|c|c|c|c|}
\hline Strain & Stress (Mpa) & Strain & Stress (Mpa) & Strain & Stress (Mpa) \\
\hline 0.0000 & 0.0000 & 0.3400 & 0.3741 & 0.6800 & 0.4434 \\
\hline 0.0100 & 0.1250 & 0.3500 & 0.3741 & 0.6900 & 0.4951 \\
\hline 0.0200 & 0.3239 & 0.3600 & 0.3741 & 0.7000 & 0.5323 \\
\hline 0.0300 & 0.3409 & 0.3700 & 0.3741 & 0.7100 & 0.5595 \\
\hline 0.0400 & 0.3651 & 0.3800 & 0.3741 & 0.7200 & 0.5953 \\
\hline 0.0500 & 0.3669 & 0.3900 & 0.3741 & 0.7300 & 0.6320 \\
\hline 0.0600 & 0.3722 & 0.4000 & 0.3741 & 0.7400 & 0.6587 \\
\hline 0.0700 & 0.3741 & 0.4100 & 0.3741 & 0.7500 & 0.6847 \\
\hline 0.0800 & 0.3741 & 0.4200 & 0.3741 & 0.7600 & 0.7360 \\
\hline 0.0900 & 0.3741 & 0.4300 & 0.3741 & 0.7700 & 0.7720 \\
\hline 0.1000 & 0.3741 & 0.4400 & 0.3741 & 0.7800 & 0.8323 \\
\hline 0.1100 & 0.3741 & 0.4500 & 0.3741 & 0.7900 & 0.8786 \\
\hline 0.1200 & 0.3741 & 0.4600 & 0.3741 & 0.8000 & 0.9575 \\
\hline 0.1300 & 0.3741 & 0.4700 & 0.3741 & 0.8100 & 1.2500 \\
\hline 0.1400 & 0.3741 & 0.4800 & 0.3741 & 0.8200 & 1.3500 \\
\hline 0.1500 & 0.3741 & 0.4900 & 0.3741 & 0.8300 & 1.4750 \\
\hline 0.1600 & 0.3741 & 0.5000 & 0.3741 & 0.8400 & 1.6000 \\
\hline 0.1700 & 0.3741 & 0.5100 & 0.3741 & 0.8500 & 1.8000 \\
\hline 0.1800 & 0.3741 & 0.5200 & 0.3741 & 0.8600 & 2.0000 \\
\hline 0.1900 & 0.3741 & 0.5300 & 0.3741 & 0.8700 & 2.3500 \\
\hline 0.2000 & 0.3741 & 0.5400 & 0.3741 & 0.8800 & 2.7500 \\
\hline 0.2100 & 0.3741 & 0.5500 & 0.3741 & 0.8900 & 3.2500 \\
\hline 0.2200 & 0.3741 & 0.5600 & 0.3741 & 0.9000 & 4.0000 \\
\hline 0.2300 & 0.3741 & 0.5700 & 0.3741 & 0.9100 & 4.7500 \\
\hline
\end{tabular}


Stress-strain curve used for modelling of foam pad (Dow Automotive, 2009) (continued):

\begin{tabular}{lccccc}
\hline Strain & Stress $(\mathrm{Mpa})$ & Strain & Stress $(\mathrm{Mpa})$ & Strain & Stress $(\mathrm{Mpa})$ \\
\hline 0.2400 & 0.3741 & 0.5800 & 0.3741 & 0.9200 & 6.0000 \\
0.2500 & 0.3741 & 0.5900 & 0.3741 & 0.9300 & 8.0000 \\
0.2600 & 0.3741 & 0.6000 & 0.3741 & 0.9400 & 15.0000 \\
0.2700 & 0.3741 & 0.6100 & 0.3741 & 0.9500 & 27.0000 \\
0.2800 & 0.3741 & 0.6200 & 0.3741 & 0.9600 & 44.0000 \\
0.2900 & 0.3741 & 0.6300 & 0.3741 & 0.9700 & 55.0000 \\
0.3000 & 0.3741 & 0.6400 & 0.3741 & 0.9800 & 66.0000 \\
0.3100 & 0.3741 & 0.6500 & 0.3741 & 0.9900 & 90.0000 \\
0.3200 & 0.3741 & 0.6600 & 0.3741 & & \\
0.3300 & 0.3741 & 0.6700 & 0.3741 & & \\
\hline
\end{tabular}

